\title{
The ethics of human impacts and the future of the earth's ecosystems: Introduction
}

\author{
Daniel Pauly ${ }^{1}$, Konstantinos I. Stergiou ${ }^{2,3, *}$ \\ ${ }^{1}$ Fisheries Centre, 2202 Main Mall, Aquatic Ecosystems Research Laboratory, The University of British Columbia, Vancouver, \\ British Columbia V6T 1Z4, Canada \\ ${ }^{2}$ Institute of Marine Biological Resources and Inland Waters, Hellenic Centre for Marine Research, Aghios Kosmas, \\ 16777 Athens, Greece \\ ${ }^{3}$ Laboratory of Ichthyology, Department of Zoology, School of Biology, Aristotle University of Thessaloniki, UP Box 134, \\ 54124 Thessaloniki, Greece
}

\begin{abstract}
In this Theme Section, a selection of the International Ecology Institute Prize laureates and authors of the Excellence in Ecology books present their thoughts on the ethics of our impact on, and the future of, the earth's ecosystems. The 5 essays address various issues: (1) the longer-term role of humans on the earth and (2) the earth's capacity for supporting humans; (3) the diversity of microbes surrounding us and the allergic desensitization they provide and (4) our need for respecting the world around us; (5) which is gradually being compromised by our inability to act as reasonable stewards of the earth. In addition, the ethics of overfishing as well as new issues and questions raised are briefly discussed.
\end{abstract}

KEY WORDS: Bioethics $\cdot$ Microbes $\cdot$ Biodiversity $\cdot$ Overfishing $\cdot$ Stewardship

\section{INTRODUCTION}

An important contribution of the International Ecology Institute (ECI; www.int-res.com/ecologyinstitute/eci-home/) to science is the publication of the Excellence in Ecology book series authored by the ECI Prize laureates (www.int-res.com/ecologyinstitute/eci-prize/). The ECI prize is awarded to ecologists who are distinguished by outstanding and sustained scientific achievement, and are therefore some of the most important marine, terrestrial, and limnetic ecologists of our time. In each book, the author is encouraged to present personal insights, freely criticize, and formulate new scientific concepts.

In this Theme Section, a selection of these authors present their thoughts on the ethics of our impact on, and the future of, the earth's ecosystems, each con-

*Corresponding author: kstergio@hcmr.gr tributing an essay either from their own field of specialization, or on wider issues they encountered in the course of their careers.

\section{ETHICS AND SCIENCE}

Ethics and science do not necessarily mix well, and a collection of essays devoted to how these 2 realms interact could be called 'transgressive' if the term had not been abused (Sokal 2008). Scientists, young and old alike, are still uncomfortable with ethics, even though they are often involved in research whose products may have profound effects, including some very negative to the well-being of people; for example, chemists involved in enhancing the taste of nutritionally worthless quasi-food products. Yet, we must deal with ethical issues, notably

() The authors 2014. Open Access under Creative Commons by Attribution Licence. Use, distribution and reproduction are unrestricted. Authors and original publication must be credited. 
because the applications alluded to above are becoming ever-more powerful, and their consequences, unintended or not, are impacting increasingly more people. Because we are scientists, however, we will start our reflection with empirical data. The empirical data we will use here should answer the question: How much concern is there about the issue of ethics in science?

A search of the relative frequencies of ethicsrelated 1-, 2-, or 3-word sequences in the corpus of digitized books, such as 'bioethics,' 'ethics in science,' 'ecoethics' (Fig. 1a), 'ethics in law,' 'ethics in politics,' and 'ethics in medicine' (not shown here) reveals that bioethics clearly dominates the frequencies by more than 2 orders of magnitude, with its frequency of use exponentially increasing after 1970 (Fig. 1a). The relative frequencies of 'ethics in science' and 'ecoethics' also increase exponentially after 1960 and the late 1980s, respectively (Fig. 1a).
In addition, the relative frequencies of 'biodiversity conservation' (all forms) and 'human impact' also increased exponentially after 1990 and 1950, respectively, whereas 'planetary capacity' and 'human overpopulation' were 1 or 2 orders of magnitude smaller (Fig. 1b).

Overall, however, what the 2 panels of Fig. 1 illustrate is that there is indeed increasing concern about the nexus of ethics and science, notably regarding human interactions with the earth's natural systems and their biodiversity. Discussions about these issues are taking place, and the important question for scientists is whether they feel comfortable with everybody except themselves having and expressing opinions about ethics and science, and particularly about the 'ethics of trashing the earth' (the only one we will have for a long time, notwithstanding the possible discovery of a second Earth in outer space).
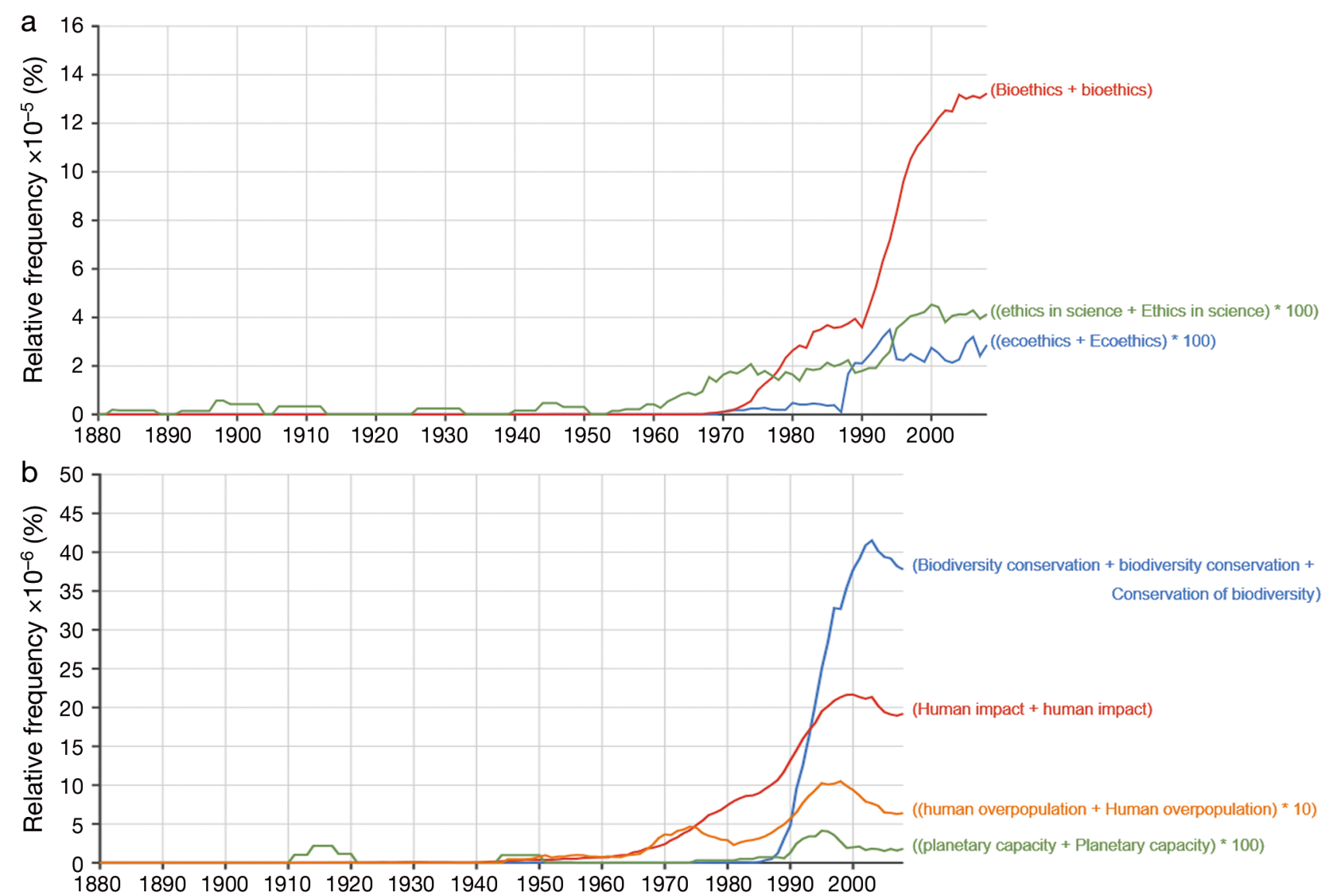

Fig. 1. Relative frequencies of different terms in the corpus of English digitized books, extracted using the Ngram Google tool (available online at http://books.google.com/ngrams). (a) All forms of 'bioethics,' 'ecoethics,' and 'ethics in science,' (b) all forms of 'biodiversity conservation,' 'human impact,' 'human overpopulation,' and 'planetary capacity.' A detailed account of the Ngram technique is provided by Michel et al. (2011) and Lin et al. (2012), whereas a step-by-step guide for its application using examples is available online at http://books.google.com/ngrams/info\#advanced 


\section{FROM ALLERGIC DESENSITIZATION TO THE CAPACITY OF EARTH TO SUPPORT HUMANS: IDEAS PUT FORWARD IN THIS THEME SECTION}

The 5 essays in this theme section address some of these issues: the longer-term role of humans on the earth (Pauly 2014) and the earth's capacity for supporting humans (Ehrlich 2014), the diversity of microbes surrounding us and the allergic desensitization they provide (Hanski 2014), and our need for respecting and loving the world around us (Loreau 2014), which is gradually being compromised by our inability to act as reasonable stewards of the earth (Reynolds 2014).

In particular, Pauly (2014) argues that humans are not 'part of the ecosystem,' as the phrase goes, but rather threaten to become 'a cancer on the Earth,' and he concludes that humans' longer-term ecological role on Earth should instead resemble that of a 'co-evolved parasite' of the earth's systems. Ehrlich (2014) discusses various ethical issues (e.g. consumption, overpopulation) associated with the $\mathrm{I}=\mathrm{PAT}$ equation, in which I is the impact of a human society on its environment, $\mathrm{P}$ is society's population size, $\mathrm{A}$ is its per capita consumption, and $\mathrm{T}$ is the 'technology' which includes the processes used to service the consumption as well as the political, social, and economic arrangements involved. Hanski (2014) discusses a special case of the biodiversity hypothesis showing a significant negative relationship between allergic sensitization in adolescents and the amount of forest and agricultural land in their surroundings, a fact clearly revealing that environmental microbial diversity is a vital health-related 'ecosystem service.' Loreau (2014) argues that human nature is neither fundamentally selfish and utilitarian nor fundamentally altruistic and non-utilitarian; humans simply have a set of fundamental needs that they perceive as needing to be satisfied. Thus, to the extent that their needs include respecting and loving the world around them, they may be motivated to act toward maintaining its biodiversity and natural ecosystems. Finally, Reynolds (2014) discusses the limited capacity of the planet to support humans, under various scenarios and assumptions and stresses that new social structures and new, cleaner, more resourceefficient technologies are required that must be directed towards solving inequities in the use of food, energy, and, especially so, water.

Several forms of human impact that have major ethical implications are not handled here, for example climate change, deforestation, soil erosion, pollution and overfishing, and all have major impacts on the delivery of services by an ecosystem, e.g. soils for farming (see Montgomery 2012), or marine fisheries. Given our fisheries background, below we take this opportunity to briefly elaborate on ethical issues regarding the last of these.

\section{OVERFISHING AND ETHICS}

Several studies have documented that many fisheries of the world are in the process of collapsing (e.g. Pauly et al. 1998, 2002, Stergiou 2002, Beddington et al. 2007, Christensen et al. 2014, Vasilakopoulos et al. 2014), despite some local fisheries, e.g. in the USA, being managed successfully. Fishing is an extractive activity that has a history going back at least $90000 \mathrm{yr}$, as demonstrated by harpoons associated with the remains of giant catfishes (Yellen et al. 1995). Fishing remained tied to muscle and wind power until the 1880 s, when the first steam trawlers were deployed around the British Isles (Roberts 2007). Given their enormous power, they quickly depleted inshore stocks of fishes and had to move offshore, into the wider North Sea and beyond. This expansion of industrial fisheries, first interrupted by World War (WW) I, then by WWII, characterizes marine fisheries development since the post-WWII period. This expansion is clearly profit-driven and mediated by rapid technological development.

Officially, marine fisheries remove around 80 million $t$ annually (FAO 2014). However, recent 'catch reconstructions' (see e.g. Zeller et al. 2011, 2014) have documented that total removals (i.e. including those of the small-scale recreational and subsistence fisheries, as well as discards, and illegal, unreported, and unregulated catches, IUUs) are well over 120 million $t$ annually, but are declining rapidly due to overfishing. There is little doubt that such a large-scale removal of biomass from our oceans drastically affects the structure and function of marine ecosystems and thus their ability to provide us with (sea)food, as well as aesthetic and cultural services (Pauly et al. 2006, Halpern et al. 2012). The detrimental effects of fishing were very illustratively expressed by Lord Perry of Walton several years ago: 'Fifty years ago, a single cod was large enough to feed a family of four or five. Today, it is barely enough for one' (Anonymous 1997, p. 110).

Such a huge removal of biomass from our oceans not only raises ethical issues related to the fate of our oceans and the right of future generations to enjoy them as their ancestors did, but also raises ethical issues at the governmental/political level related to the intended (or unintended) underreporting of official landings. 
Mariculture, seen by many as the future of seafood provisioning, will not be able to fulfill its potential if it continues to shift toward the production of carnivorous fishes, which require smaller fishes for their feed (Pauly et al. 2001, Stergiou et al. 2009, Tsikliras et al. 2014). In fact, mariculture, and aquaculture as a whole, when it shifts from raising mussels, oysters, and other plankton feeders toward the farming of carnivorous fish such as salmon, changes from being part of the solution to feeding the world, to generating new socioeconomic and ethical concerns. This is because large quantities of fishes suitable for direct human consumption are turned into animal feed, used for the production of relatively small quantities of fishes destined for affluent consumers (Naylor et al. 2000).

\section{EPILOGUE}

This Theme Section also raises new issues and questions that will have to be answered in the near future. For instance, resolving inequities in resource use requires strong political will at the global level. Yet, it is well accepted that there is a lack of political will (Cardinale \& Svedäng 2008), with politics being the weak link in management (Browman \& Stergiou 2005). In addition, the recent imposed globalization (Friedman 2005), liberalization, and marketization of all aspects of our lives, from markets, agriculture, and fisheries to the last 'public fortress' of our societies, i.e. our educational system (Lynch 2014, Stergiou \& Tsikliras 2014), also raise the question of whether equities in resource use can be achieved, rather than increasing the chasm in resource use between north and south, and within each country, between its rich and poor citizens.

Unquestionably, changing our consumption patterns and resolving the issues presented in this Theme Section, and others, will take many generations and will require the education of new generations of scientists and informed citizens. Also, public servants and politicians will need to be sensitized to environmental problems and the ethical issues they raise. However, one has to wonder whether this can be achieved within the new global landscape of declining academic freedom arising from the marketization of education (Stergiou \& Tsikliras 2014).

Finally, economic crises are confronted with drastic, severe measures, as is clearly exemplified by the recent economic crisis in southern European countries. In contrast, global ecological crises, such as those described here, are not taken as seriously as economic crises, despite their many similarities, a fact that might lead to ecosystem/resource crises, and thus to ecosystem bankruptcy with severe side effects on global economy (Tsikliras et al. 2013). The question is still open of whether ecological crimes (i.e. pollution, IUU fishing; sensu Österblom et al. 2011) leading to ecological crises should be confronted with measures of similar severity (Tsikliras et al. 2013). The International Monitoring, Control, and Surveillance network and the INTERPOL Environmental Crime Committee (with permanent Fisheries, Wildlife and Pollution Crime working groups; Österblom 2014) represent a step in the right direction.

Maybe the best way to close this essay is with the well-known ancient Greek phrase 'metron ariston' ('everything in moderation'), since the extravagant ways we have used to despoil our planet have made it a subversive adage.

\section{LITERATURE CITED}

Anonymous (1997) Fishing by numbers reveals its limits. Nature 386:110

Beddington JR, Agnew DJ, Clark CW (2007) Current problems in the management of marine fisheries. Science 316:1713-1716

Browman HI, Stergiou KI (eds) (2005) Politics and socioeconomics of ecosystem-based management of marine resources. Mar Ecol Prog Ser 300:241-296

Cardinale M, Svedäng H (2008) Mismanagement of fisheries: policy or science? Fish Res 93:244-247

Christensen V, Coll M, Piroddi C, Steenbeek J, Buszowski J, Pauly D (2014) A century of fish biomass decline in the ocean. Mar Ecol Prog Ser 512:155-166

Ehrlich PR (2014) Human impact: the ethics of I=PAT. Ethics Sci Environ Polit 14:11-18

FAO (Food and Agriculture Organization of the United Nations) (2014) The state of world fisheries and aquaculture. FAO, Rome

Friedman TL (2005) The world is flat, 1st edn. Farrar, Straus and Giroux, New York, NY

Halpern BS, Longo C, Hardy D, McLeod K and others (2012) An index to assess the health and benefits of the global ocean. Nature 488:615-620

Hanski I (2014) Biodiversity, microbes and human wellbeing. Ethics Sci Environ Polit 14:19-25

Lin Y, Michel JB, Aiden EL, Orwant J, Brockman W, Petrov S (2012) Syntactic annotations for the Google Books Ngram corpus. Proc 50th Annu Meet Assoc Computational Linguistics Vol 2: Demo Papers, ACL, Jeju, 8-14 July 2012

> Loreau M (2014) Reconciling utilitarian and non-utilitarian approaches to biodiversity conservation. Ethics Sci Environ Polit 14:27-32

Lynch K (2014) New managerialism, neoliberalism and ranking. Ethics Sci Environ Polit 13:141-153

Michel JB, Shen YK, Aiden AP, Veres A and others (2011) Quantitative analysis of culture using millions of digitized books. Science 331:176-182

Montgomery DR (2012) Dirt: the erosion of civilizations. University of California Press, Berkeley, CA 
Naylor RL, Goldburg RJ, Primavera JH, Kautsky N and others (2000) Effect of aquaculture on world fish supplies. Nature 405:1017-1024

Österblom H (2014) Catching up on fisheries crime. Conserv Biol 28:877-879

Österblom H, Constable A, Fukumi S (2011) Illegal fishing and the organized crime analogy. Trends Ecol Evol 26: 261-262

Pauly D (2014) Homo sapiens: cancer or parasite? Ethics Sci Environ Polit 14:7-10

Pauly D, Christensen V, Dalsgaard J, Froese R, Torres F Jr (1998) Fishing down marine food webs. Science 279: 860-863

Pauly D, Tyedmers P, Froese R, Liu LY (2001) Fishing down and farming up the food web. Conserv Biol Pract 2:25

Pauly D, Christensen V, Guénette S, Pitcher TJ and others (2002) Towards sustaninability in world fisheries. Nature 418:689-695

Pauly D, Alder J, Bakun A, Heileman S and others (2006) Marine fisheries systems. In: Baker J, Moreno Casasola P, Lugo A, Suárez Rodríguez A, Ling Tang LD (eds) Millennium ecosystem assessment: ecosystems and human well-being. A framework for assessment: condition and trends. Island Press, Washington, DC, p 477-511

Reynolds CS (2014) On the planetary capacity to sustain human populations. Ethics Sci Environ Polit 14:33-41

Roberts C (2007) The Unnatural history of the sea: the past and future of humanity and fishing. Island Press, Washington, DC
Sokal A (2008) Beyond the hoax: science, philosophy and culture. Oxford University Press, Oxford

Stergiou KI (2002) Overfishing, tropicalization of fish stocks, uncertainty and ecosystem management: resharpening Ockham's razor. Fish Res 55:1-9

Stergiou KI, Tsikliras AC (2014) Global university rankings uncovered. Ethics Sci Environ Polit 13:59-64

Stergiou KI, Tsikliras AC, Pauly D (2009) Farming up the Mediterranean Sea. Conserv Biol 23:230-232

- Tsikliras AC, Sumaila UR, Stergiou KI (2013) Parallels in economic and ecosystem crises. Ethics Sci Environ Polit $13: 23-25$

Tsikliras AC, Stergiou KI, Adamopoulos N, Pauly D, Mente E (2014) Shift in trophic level of Mediterranean mariculture species. Conserv Biol 28:1124-1128

Vasilakopoulos P, Maravelias CD, Tserpes G (2014) The alarming decline of Mediterranean fish stocks. Curr Biol 24:1643-1648

Yellen JE, Brooks AS, Cornelissen E, Mehlman MJ, Stewart K (1995) A middle stone-age worked bone industry from Katanda, Upper Semliki Valley, Zaire. Science 268: 553-556

Zeller D, Rossing P, Harper S, Persson L, Booth S, Pauly D (2011) The Baltic Sea: estimates of total fisheries removals 1950-2007. Fish Res 108:356-363

Zeller D, Harper S, Zylich Z (2014) Synthesis of underreported small-scale fisheries catch in Pacific-island waters. Coral Reefs (in press) doi:10.1007/s00338-0141219-1 